\title{
Variability of the North Atlantic eddy-driven jet stream
}

Article

Accepted Version

Woollings, T., Hannachi, A. and Hoskins, B. (2010) Variability of the North Atlantic eddy-driven jet stream. Quarterly Journal of the Royal Meteorological Society, 136 (649). pp. 856-868. ISSN 1477-870X doi: https://doi.org/10.1002/qj.625 Available at https://centaur.reading.ac.uk/8175/

It is advisable to refer to the publisher's version if you intend to cite from the work. See Guidance on citing.

Published version at: http://dx.doi.org/10.1002/qj.625

To link to this article DOI: http://dx.doi.org/10.1002/qj.625

Publisher: Royal Meteorological Society

All outputs in CentAUR are protected by Intellectual Property Rights law, including copyright law. Copyright and IPR is retained by the creators or other copyright holders. Terms and conditions for use of this material are defined in the End User Agreement.

\section{www.reading.ac.uk/centaur}

\section{CentAUR}

Central Archive at the University of Reading

Reading's research outputs online 


\title{
Variability of the North Atlantic eddy-driven jet stream
}

\author{
Tim Woollings, Abdel Hannachi and Brian Hoskins \\ Department of Meteorology, University of Reading, Earley Gate, PO Box 243, Reading, RG6 6BB, UK. t.j.woollings@ reading.ac.uk
}

\begin{abstract}
:
Much of the atmospheric variability in the North Atlantic sector is associated with variations in the eddy-driven component of the zonal flow. Here we present a simple method to specifically diagnose this component of the flow using the low-level wind field $(925-700 \mathrm{hPa})$. We focus on the North Atlantic winter season in the ERA-40 reanalysis. Diagnostics of the latitude and speed of the eddy-driven jet stream are compared with conventional diagnostics of the North Atlantic Oscillation (NAO) and the East Atlantic (EA) pattern. This shows that the NAO and the EA both describe combined changes in the latitude and speed of the jet stream. It is therefore necessary, but not always sufficient, to consider both the NAO and the EA in identifying changes in the jet stream.

The jet stream analysis suggests that there are three preferred latitudinal positions of the North Atlantic eddy-driven jet stream in winter. This result is in very good agreement with the application of a statistical mixture model to the two-dimensional state space defined by the NAO and the EA. These results are consistent with several other studies which identify four European/Atlantic regimes, comprising three jet stream patterns plus European blocking events.

Copyright (C) 2009 Royal Meteorological Society

KEY WORDS

Received ; Revised ; Accepted
\end{abstract}

\section{Introduction}

Much of the weather and climate of the extratropics is associated in some way with the midlatitude westerly jet streams. There are essentially two physical processes which give rise to the jet streams. The first is the westerly acceleration associated with poleward moving air in the upper branch of the tropical Hadley circulation, consistent with the local vorticity balance. This results in a westerly jet stream at upper levels at the poleward edge of the Hadley cell. The second is the momentum and heat forcing arising from the effects of transient midlatitude eddies. Because of these two mechanisms, it is common to refer to two different jet streams, named the subtropical and eddy-driven jets respectively. In many instances there is no spatial separation between the two jets, but even then the conceptual separation is still useful in many regards.

Flow variability is largest over the ocean basins where the jets, in particular the eddy-driven jets, are strongest (Blackmon 1976). Most of the major extratropical teleconnection patterns essentially represent jet stream variability 
(Wittman et al. 2005; Monahan and Fyfe 2006). Over the North Atlantic, the North Atlantic Oscillation (NAO) has been the dominant component of variability over recent decades, but the East Atlantic pattern (EA) is also important. This variability is usually described by patterns in pressure or geopotential height fields, but in many respects a direct analysis of the wind field seems more natural (Athanasiadis et al. 2009).

Several authors have recently developed techniques to identify and characterise jet streams directly in the upper level wind field (e.g. Koch et al. 2006; Strong and Davis 2008; Barton and Ellis 2009). The aim of this paper is similar, but with the difference that here we attempt to diagnose the eddy-driven component of the wind field specifically. This is motivated by a large body of work over recent years showing that the variability associated with patterns such as the NAO reflects changes in the eddy-driven component, since variability in the eddy forcing itself contributes to the wind variations (e.g. Thompson et al. 2002; Lorenz and Hartmann 2003; Bordi et al. 2007; Vallis and Gerber 2008).

One of the key differences between the two jets is in their vertical structure. The subtropical jet is relatively shallow and confined to the upper troposphere, at the level of the upper branch of the Hadley cell. In contrast, the eddy-driven jet extends throughout the depth of the troposphere, due to the action of transient eddy forcing to particularly accelerate the westerlies at low levels, thus barotropising the flow (e.g. Hoskins et al. 1983). This suggests that the eddy-driven jet stream is best diagnosed from the wind at lower levels, and this is the approach we take here.

We present results of a simple analysis of the variability of the low-level wind in the ERA-40 reanalysis data (Uppala et al. 2005). This analysis derives daily time series of the strength and the latitudinal position of the eddydriven jet stream. We focus on the North Atlantic jet in winter, but some comparison is made to results in other seasons and sectors. Two applications of this analysis are also given. Firstly, we analyse the distribution of the jet stream latitude for evidence of preferred locations of the jet stream. There has been much debate over the existence and significance of distinct atmospheric flow regimes (e.g. Christiansen 2007). The existence of preferred jet stream locations would provide a good physical interpretation of such regimes, and may suggest possible underlying dynamical causes. Secondly, we relate the jet stream diagnostics to familiar patterns of variability, in particular the NAO and the EA.

\section{Diagnosing jet latitude and speed}

The latitude and speed of the eddy-driven jet stream is identified in daily ERA-40 wind data over the period 1 December 1957 - 28 February 2002. This provides 45 complete winter seasons (DJF) of data but only 44 complete seasons in spring (MAM), summer (JJA) and autumn (SON). The algorithm proceeds as follows:

1. The daily mean zonal wind is averaged over the levels $925,850,775$ and $700 \mathrm{hPa}$.

2. The resulting field is then zonally averaged over a longitudinal sector $\left(0-60^{\circ} \mathrm{W}\right.$ for the North Atlantic), neglecting winds poleward of $75^{\circ}$ and equatorward of $15^{\circ}$.

3. The resulting field is then low-pass filtered to remove the features associated with individual synoptic systems. This is done using a 10 day Lanczos filter with a window of 61 days (Duchon 1979).

4. The maximum westerly wind speed of the resulting profile is then identified and this is defined as the jet speed. The jet latitude is defined as the latitude at which this maximum is found. 
5. Smooth seasonal cycles of the jet latitude and speed are defined by averaging over all years and then Fourier filtering, retaining only the mean and the two lowest frequencies. The jet latitude and speed as presented here are anomalies from the seasonal cycle.

The method is robust to changes in many features of the algorithm. This formulation ensures relatively little noise in the resulting diagnostics, but the main results are not changed qualitatively if, for example, the low-pass filtering is omitted, or the wind at just one level is used. Using only the surface wind also gives very similar results. In fact, the only parameter to which the results are qualitatively sensitive is the choice of longitudinal sector. This is discussed in more detail below. The seasonal cycle of jet latitude is relatively small, with the jet lying on average $4^{\circ}$ further north in summer than in winter. The seasonal cycle of jet speed is relatively larger, with average wind speeds of $14 \mathrm{~ms}^{-1}$ in winter and $10 \mathrm{~ms}^{-1}$ in summer. If the seasonal cycle is not removed, the distribution of jet latitude within each individual season is only slightly changed. Winds poleward of $75^{\circ}$ are neglected to reduce the false detection of smallscale wind extrema, often associated with orography or coastlines, that have a large influence on sector means at high latitudes where meridians are converging. In the East Pacific sector used in the Appendix, this parameter is set to $65^{\circ} \mathrm{N}$ to restrict the influence of the Alaskan orography.

We begin by showing in Figure 1 the distribution of the jet latitude anomaly for the North Atlantic $\left(0-60^{\circ} \mathrm{W}\right)$ in winter. The distribution has considerable structure, with three clear maxima well separated by minima. This is highly suggestive that there are three preferred locations of the North Atlantic eddy-driven jet stream. The trimodality of the distribution is robust to sub-sampling of the data, for example if only the first or the second half of the ERA-40 period is used. Throughout this paper the kernel method of Silverman (1981) has been used to estimate probability density functions (PDFs). The standard smoothing parameter $h=1.06 \sigma n^{-1 / 5}$ has been used, where $\sigma$ is the standard deviation and $n$ is the sample size. However, even if the maximal smoothing principle of Terrell (1990) is applied the multimodality in Figure 1 remains (not shown). This method (using $h=1.14 \sigma n^{-1 / 5}$ ) gives a conservative oversmoothed PDF, so the fact that multimodality remains here shows that this result has very high statistical significance. Interestingly, the trimodal distribution of jet latitude is unique to the North Atlantic, although bimodal behaviour is in evidence elsewhere. See the Appendix for a summary of the results of this method applied to other regions and to other Atlantic seasons. For completeness we have applied the Silverman (1981) test for multimodality to all of the PDFs, and this is also reported in the appendix.

The trimodality should clearly be tested using other methods of analysis. One of the least satisfactory aspects of the method presented here is the need to average over a sector of longitude. This is especially questionable in the North Atlantic where the jet stream tilts southwest-northeast and, as mentioned above, the choice of sector is the only aspect of the method to which the result of a trimodal distribution is sensitive. To test this result we devised a method, based on that of Strong and Davis (2008), to identify jet events in both latitude and longitude. The method uses 10 day low-pass filtered wind averaged over $925-700 \mathrm{hPa}$ as before, although here both zonal and meridional components of the wind are combined to give the wind speed. Maxima in wind speed along each meridian are identified as jet events, provided the zonal wind is westerly and the wind speed is at least $8 \mathrm{~ms}^{-1}$. The results are not sensitive to reasonable 
variations in this parameter. The presence of orography leads to considerable noise, so the analysis is restricted to points at least two grid cells away from land.

The occurrence of jet events identified by this method is shown in Figure 2. There are two clear bands of frequently occurring jet events centred near $37^{\circ} \mathrm{N}$ and $45^{\circ} \mathrm{N}$. This method, which does not require averaging in longitude, therefore supports the existence of preferred jet stream locations. There is a third region of frequent occurrence to the north, although this is less clearly separated from the central location. In section 4 we will present another analysis which also suggests the same three preferred jet locations, but with weaker significance for the northern location. This method allows the existence of more than one jet event along each meridian, in contrast to the jet latitude algorithm described above. The results shown in Figure 2 show that the exclusion of any secondary wind maxima does not affect the finding of multimodality. We have examined the occurrence of secondary maxima found using the jet latitude algorithm. These are found to be at least one standard deviation* weaker than the largest maximum on $67 \%$ of occasions when a secondary maximum exists, and separated from the largest maximum by at least $10^{\circ}$ of latitude on $84 \%$ of occasions.

We end this section with an illustration of the jet stream latitude method in Figure 3, which shows Hovmöller plots of the vertically and sector averaged wind, along with the jet latitude identified by the algorithm. Both the unfiltered and the 10-day low-pass winds are shown, for the last winter season in the dataset. Seasonal mean estimates of the three preferred jet latitudes were derived by adding the seasonal mean latitude onto the PDF from Figure 1. The Hovmöllers show that the jet stream is always evident as a coherent region of westerly wind, and the method successfully follows the jet stream as it shifts north and south. The low-pass filtering has not distorted the general pattern of wind variations.

\section{Three preferred jet stream locations}

In this section we describe the three preferred jet stream locations by presenting composites of the 300 days with jet latitude anomalies closest to each of the three maxima in the PDF of Figure 1. Composites of unfiltered daily geopotential height anomalies at $500 \mathrm{hPa}$ (Z500) are shown in Figure 4. The daily Z500 anomalies were derived by removing a smooth seasonal cycle, calculated by averaging over all years and then filtering with a discrete cosine transform, retaining only the mean and the lowest two frequencies.

The anomalies associated with the southern jet location are very similar to the negative pattern of the NAO. The correspondence of this pattern to a preferred jet stream location is in agreement with Woollings et al. $(2008,2009)$ who suggested the existence of a distinct negative-NAO regime corresponding to high-latitude blocking over Greenland. The central and northern jet stream locations have Z500 patterns closely resembling the positive and negative phases of the East Atlantic pattern. Interestingly, neither of these two anomaly patterns particularly resemble the positive NAO pattern although, as will be shown later, both do have weak positive projections onto the NAO. In all cases, anomalies outside the Atlantic sector are weak. Given that the central jet stream location is relatively close to the time-mean location (Figure 1) it might be considered surprising that this composite has anomaly values of a similar magnitude to

* One standard deviation of the jet speed time series is $4 \mathrm{~ms}^{-1}$. 
the other two composites. As shown later, this reflects the significant difference between the mean flow and the most frequented flow pattern.

Many studies have applied regime detection methodologies to Z500 reanalysis data, so Figure 4 allows a comparison with these studies. Several studies suggest there are four preferred flow regimes in the North Atlantic/European sector (e.g. Vautard 1990; Michelangeli et al. 1995; Cassou et al. 2004). These regimes generally correspond to three mid-Atlantic patterns and a pattern representing European blocking. This is consistent with the results presented here, since we analyse the sector $0-60^{\circ} \mathrm{W}$ only, so European blocking does not appear directly in this analysis (see below). In some of these studies the agreement with the three anomaly patterns in Figure 4 is strong (e.g. Cassou 2008)

Composites of zonal wind averaged over $0-60^{\circ} \mathrm{W}$ are shown in Figure 5. In both the central and northern jet composites the eddy-driven jet is clearly separated from the subtropical jet. Only in the southern jet location is there not a clear separation between the two jets. In contrast to the subtropical jet, the eddy-driven jet extends down to the surface. It has an equivalent barotropic structure, confirming that the latitude of the low-level winds is representative of the location of the jet stream. However, the wind speed increases with height, so that the upper level wind is much stronger than that at the surface. The horizontal structure of the jet streams is shown by compositing $250 \mathrm{hPa}$ zonal wind for each of the jet stream locations in Figure 6. As the jet stream shifts north its southwest-northeast tilt increases, so that the latitude and orientation of the jet vary together. This tilt implies that the eddy-driven jet is in general narrower than appears in the sector mean shown in Figure 5.

Figure 6 also shows the transient eddy forcing of westerly momentum, as described by $\mathbf{E}$-vectors $(\mathbf{E}=$ $\left(\overline{v^{\prime 2}-u^{\prime 2}}, \overline{-u^{\prime} v^{\prime}}\right)$; Hoskins et al. 1983) of the $250 \mathrm{hPa} 2-6$ day bandpass filtered winds $u^{\prime}$ and $v^{\prime}$ (using a Lanczos filter with a 60 day window). Regions with diverging $\mathbf{E}$-vectors experience acceleration of the westerlies by transient eddy momentum fluxes. In each of the three composites the region of divergence aligns well with the wind anomalies. This confirms that, on average, the effect of the transient eddies is to reinforce the eddy-driven jet stream at its current location. The transient eddy kinetic energy (not shown) follows the jet stream and the regions of diverging $\mathbf{E}$-vectors very closely. This shows that the eddies in general propagate along the jet stream, and deform so as to flux westerly momentum into the jet stream core (Hoskins et al. 1983). At first sight this seems to suggest a mechanism for the existence of the preferred jet locations. However, similar composites of days near the two minima in the jet latitude PDF are very similar (not shown). The transient eddy forcing acts to reinforce the jet at these locations as much as at the three maxima of the PDF.

While the average effect of transient eddy forcing is to maintain the jet at its current location, variations in the eddy forcing lead to meridional shifts of the jet stream (e.g. Lorenz and Hartmann 2003; Vallis and Gerber 2008). The eddyforcing shown in Figure 6 is likely a mixture of the burst of eddy fluxes which created the anomaly and the subsequent fluxes which maintain it. Several studies have linked variations in eddy forcing with Rossby wave breaking events (Benedict et al. 2004; Franzke et al. 2004; Rivière and Orlanski 2007; Martius et al. 2007; Strong and Magnusdottir 2008; Kunz et al. 2009). Woollings et al. (2008) suggested a particular importance of wave-breaking events more 
persistent than the 2-6 day transients in Figure 6, which bear many of the hallmarks of blocking. During these 'Greenland blocking' events a large mass of subtropical air is moved north across the jet in a large-scale wave-breaking event. At high latitudes this air mass resembles a blocking anticyclone, diverting the jet stream to the south. The situation is identified as a distinct regime in several objective analyses (Woollings et al. 2009), and decays with the characteristically long timescale of blocking (Masato et al. 2009).

To examine the relation between the preferred jet locations and persistent wave-breaking events, we show in Figure 7 composites of the wave-breaking index used by Woollings et al. (2008). This index identifies a reversal of the meridional gradient of potential temperature on the dynamical tropopause. Time and space scales are applied to ensure that the events identified are large-scale, quasi-stationary and persistent, so they are referred to as blocking events (Pelly and Hoskins 2003). Note that since the index identifies the point of the reversal of the gradient, the blocking anticyclone lies to the north of this point. As expected, the southern jet location is associated with a high occurrence of blocking over the Northwest Atlantic. This is the signature of Greenland blocking, so the correspondence between this and the southern preferred jet location seems clear. When the jet is in its central location, Figure 7 shows that there is a reduced occurrence of blocking over central western Europe (with the associated anticyclone lying north of the UK). When such blocking occurs, the jet is diverted to the north or the south or is split in both directions. Finally, in the northern jet location there is reduced occurrence of Greenland blocking, as might be expected, but also increased occurrence of blocking over southwest Europe (with the associated anticyclone over western Europe). Persistent blocking in this location would indeed act to divert the jet stream to the north, and could be responsible for the existence of the preferred northern jet location. This could resolve the question naturally arising from Woollings et al. (2008), as to why anticyclonic wave-breaking does not lead to persistent blocking-like anomalies which affect the NAO in the same way as the cyclonic Greenland blocking events. Blocking over southwest Europe will tend to be anticyclonic, and does displace the jet stream, but the resulting anomalies project strongly onto the East Atlantic pattern and only weakly onto the NAO.

To clarify the relationships between European blocking and the preferred jet latitudes, Figure 8 shows PDFs of the jet latitude during days when blocking occurs in different regions. During Greenland blocking, the jet is usually close to the southern preferred location, and similarly during blocking over Southwest Europe the jet is usually close to the northern preferred location. The grid points used to represent blocking in these locations were chosen to be close to the maximum anomaly values in Figure 7, so this is not surprising. However, we also show a PDF for blocking at a point close to the climatological maximum blocking frequency ${ }^{\dagger}$ over Europe $\left(53^{\circ} \mathrm{N}, 15^{\circ} \mathrm{E}\right.$; line EU in Figure 8$)$, when the anticyclone lies over Scandinavia. Interestingly, blocking here occurs for all jet latitudes, so it is remarkably decoupled from the latitude of the Atlantic jet stream. In this way the results presented here are indeed consistent with studies identifying a European blocking regime in addition to three jet stream regimes.

Further insight into the variability of the jet stream is given by consideration of the tendencies of the jet latitude diagnostic. Tendencies have been derived by simple centred differencing in time, and are shown in Figure 9 for both

†See Figure 2 of Woollings et al. (2008). 
the three maxima and the two minima of the jet latitude PDF. In all cases the distribution of tendency is centred around zero, so there is no clear preferred direction of the tendency. There are, however, considerable differences in the spread, reflecting differences in persistence. Days near the central maximum of the jet latitude PDF generally have weaker tendencies than other days. The central preferred jet latitude, which is distinct from the climatology, could therefore be interpreted as the undisturbed, or 'basic' state of the jet. The southern jet location exhibits the next weakest tendencies, in agreement with the persistence of this pattern as shown by Woollings et al. (2008, 2009), Masato et al. (2009) and Barnes and Hartmann (2009). Days near the two minima exhibit wider spreads of tendency, suggesting these situations are less persistent.

The significance of differences in the tendencies has been assessed by using a bootstrap method to calculate confidence intervals on the mean of the absolute values of the tendencies of each set. To account for the autocorrelation of the data, this was performed by randomly selecting (with replacement) 60 days from the 300 in each set. The mean of the absolute tendencies was calculated for each of 10000 such trials, and the differences between the sets of days are only considered significant when their \pm 1 standard deviation confidence intervals do not overlap. By this measure the only significant differences are that the central jet position exhibits weaker tendencies than both the southern minima and the northern jet position. This gives some support to the interpretation of the central jet position as the undisturbed state of the system.

Visual inspection of the Hovmöllers in Figure 3 also gives the impression that the jet persists longer at the three preferred latitudes than at other latitudes. There are interesting occasions when the jet latitude changes suddenly, such as occurs near day 40. Prior to this the jet has been moving poleward over a period of around 10 days, and as the winds at high latitudes weaken, the jet latitude jumps to follow a new pulse of westerly wind near $45^{\circ} \mathrm{N}$. Referring to instantaneous maps shows that the poleward shifted jet is dominated by a pulse of westerly wind which by this time is located to the north of Scotland. This decays over the next few days while a new pulse of westerly wind moves further south across the Atlantic from upstream.

Regime behaviour is often associated with chaotic transitions in time from one regime to another. However, the impression given here is subtley different. The jet stream shifts north or south in response to partly chaotic eddy forcing, and then this anomaly tends to persist for several days before decaying. It is the persistence of jet stream shifts which seems to lead to the regime-like preferred jet stream positions.

\section{The NAO/EA space}

From Figure 4 it is clear that the NAO alone does not describe all of the variations of the eddy-driven jet stream. In particular, the East Atlantic pattern (EA) is also important. This is consistent with Fyfe and Lorenz (2005) and Sparrow et al. (2009), who showed that in general more than one pattern is required to represent a jet of constant speed shifting in latitude. Also Monahan and Fyfe (2006) showed that each of the leading EOFs of a variable jet stream generally represent a combination of changes in the latitude, speed and width of the jet. In this section we examine the 
two-dimensional state space spanned by the NAO and the EA and compare this to the jet stream diagnostics derived above.

The NAO and EA patterns were defined as the first and second EOFs of DJF monthly mean Z500 over the Atlantic sector $75^{\circ} \mathrm{W}-15^{\circ} \mathrm{E}, 20-90^{\circ} \mathrm{N}$. In order to introduce the NAO/EA space we show the two patterns, and also linear combinations of them, in Figure 10. The $300 \mathrm{hPa}$ zonal wind associated with these patterns, obtained by regression onto the principal component time series, is also shown. The familiar NAO and EA geopotential height patterns are seen at centre right and top centre respectively. Linear combinations of these patterns are shown at the respective corner panels and generally resemble meridionally shifted NAO patterns. Such patterns are often seen in the literature (e.g. Lau 1988; Franzke and Feldstein 2005). They represent changes in the jet stream which need both the NAO and EA patterns to describe them. The $300 \mathrm{hPa}$ zonal wind shows how changes in the two patterns together describe changes in the jet stream. Starting at the NAO- panel (centre left) and moving clockwise around the panels describes a poleward shift and increasing tilt of the eddy-driven jet. At the same time the jet extends eastward until the the NAO+ panel is passed, after which it retracts again. In terms of the wind speed in the central Atlantic, this is lowest in the bottom left panel (NAO-/EA-) and highest in the top right panel (NAO+/EA+).

We now compare the NAO/EA space with the jet stream diagnostics of section 2. Figure 11 shows the scatterplot of daily values of the NAO and EA indices, obtained by projecting the daily Z500 anomaly data onto the NAO and EA patterns. The colour of each point represents the jet stream latitude and speed as defined in section 2. The correspondence between the two methods of analysis is clear. The jet is at its southernmost on NAO- days, and as the jet moves poleward from here the system moves clockwise around the NAO/EA state space. In the NAO-/EA- quadrant there is a discontinuity in jet latitude. In this sector the strongest winds can be found either on the northern flank of the anticyclonic anomaly in Figure 10 (bottom left), or on the southern flank of the cyclonic anomaly. As for the jet speed, this is at its lowest in the NAO-/EA- quadrant, and increases in all directions from there.

It is clear that together the NAO and EA describe variations in the latitude and strength of the eddy-driven jet stream. If the system changes from one location in NAO/EA space to another, we have a good estimate of the change in both the latitude and strength of the jet. However, if just one of the NAO or EA is known the situation is ambiguous. For example, consider a situation where the NAO index increases from 0 to 1 . If the EA index is 1, this change represents a northward shift of the jet, but if the EA index is -1 it represents a southward shift. This shows that both the NAO and the EA indices are necessary to describe changes in the eddy-driven jet stream, although they are not always sufficient to do this, for example in the vicinity of the sharp transition in jet latitude in the NAO-/EA- quadrant. Interestingly, there seem to be relatively few days in this sector in any case.

The scatterplots in Figure 11 suggest there is considerable structure in the distribution of points in NAO/EA space, with the distribution spreading more in the NAO- and EA- directions than NAO+ and EA+. To examine this we show in Figure 12 the two-dimensional PDF, estimated using the kernel method applied in two dimensions. Following Hsu and Zwiers (2001) the PDF is compared to 1000 synthetic distributions generated by AR1 models of the NAO and EA. These models are derived from the lag-1 autocorrelation of the NAO and EA, determined from exponential fits 
to the autocorrelation functions at a lag of 5 days, as suggested by Keeley et al. (2009). Shading in Figure 12 marks regions of NAO/EA space where the observed PDF is outside the 95\% range of the AR1 models, using a two-sided test. In none of the individual AR1 simulations are there as many points outside this range as there are in the observed series.

The shape of the PDF supports the visual impression of the structure of the distribution given by the scatterplots. The peak of the PDF lies in the NAO+/EA+ quadrant and skewness is clear along both the NAO (as in Woollings et al. 2009) and EA axes. There are two spurs of high probability extending in the negative NAO and EA directions from the peak of the PDF. There is a region of low probability in the NAO-/EA- quadrant at small magnitudes. In general these features of the PDF are significantly different from the set of AR1 simulations. As in Fyfe and Lorenz (2005), the structure in the PDF shows that the first two EOFs are clearly not independent, even though they are linearly uncorrelated.

Two-dimensional distributions such as this have often been used in the search for preferred states of the system (e.g. Corti et al. 1999; Kravtsov et al. 2006). Given the close association between the NAO/EA space and variability of the eddy-driven jet stream we now analyse this distribution for evidence of regime behaviour. To begin we simply plot in Figure 12 the locations of the three composites corresponding to the maxima of the jet latitude PDF. These locations were derived by projecting the composite maps from Figure 4 onto the NAO and EA patterns. The three preferred jet latitude composites are located in regions of unusually high probability in NAO/EA space. The central jet composite is located near the peak of the PDF, away from the origin which marks the mean of the distribution. This explains the surprisingly large anomalies associated with this composite in Figure 4. The southern jet position lies on the negative NAO spur of the PDF, corresponding to the Greenland blocking regime of Woollings et al. (2009). The northern jet position lies on the negative EA spur.

We now apply a two dimensional version of the Gaussian mixture model of Hannachi (2007) to the NAO/EA distribution. The mixture model attempts to estimate the observed distribution as a mixture of a number of different Gaussian distributions. The method was developed to overcome limitations identified in earlier regime analyses by Christiansen (2007). It avoids the need to estimate the number of independent samples and is robust to the sample size of the dataset. The method is a straightforward extension of the 1D version described by Woollings et al. (2009). The approach taken is to repeatedly add another Gaussian component while the mixing proportions are significantly different from zero at the 95\% level. The 2D Gaussian components are defined by their means and variances in two orthogonal directions (not necessarily the NAO and EA directions).

Figure 13 shows the mixing proportions for three mixture models with two to four components, along with $95 \%$ confidence limits. This shows that only three Gaussians are needed to represent the observed distribution, as the mixing proportion of the fourth component is not significantly different from zero. The three mixture model components are indicated, along with the PDF estimated by the mixture model, in Figure 14a. The three components are located over the peak of the PDF and the two spurs. The centres of the components are located at very similar positions to the locations of the three preferred jet latitude composites. This is shown in Figure 15 which compares the mixture model 
result with the jet latitude analysis. The centres of the three Gaussian components are in very good agreement with the locations of the three preferred jet locations.

The strong agreement between the results of the mixture model and the jet stream diagnosis supports the existence of three preferred locations of the eddy-driven jet stream. While this result seems clear, we have also tested a new method to assess the significance of the mixture model representation. This method is based on the reproducibility of the results in subsets of the original data, and is a more severe test of significance (see Hannachi 2009). This test suggests that, at the 95\% level, only two Gaussians are needed to model the NAO/EA distribution (not shown). The resulting Gaussian mixture with just two components is shown in Figure 14b. The components associated with the central and northern jet positions have merged, leaving the negative NAO / Greenland blocking component virtually unchanged. The system has effectively collapsed into the two regime system along the NAO axis proposed by Woollings et al. (2009), comprising a state with a separated subpolar jet and a Greenland blocking regime.

\section{Conclusions}

In this paper we have analysed simple diagnostics of the latitude and strength of the eddy-driven jet stream, as identified in the low-level zonal wind field. We have focused on the North Atlantic in winter, though a brief comparison with other regions and seasons is given in the appendix. Using the low-level wind to identify the eddy-driven, as distinct from the subtropical jet stream appears to have been successful. This is evidenced by the coherence of the relationship between the resulting diagnostics and the NAO and EA patterns (Figure 11) which are known to reflect jet stream changes resulting from variations in eddy forcing.

One of the main conclusions is that the NAO alone does not necessarily provide a good description of changes in the jet stream. Both the NAO and the EA patterns are required to indicate changes in the latitude and/or strength of the jet stream. If only information on one of these is available the effect on the jet stream could be ambiguous.

We have presented strong evidence, using several different methods of analysis, that there are three preferred latitudinal positions of the North Atlantic eddy-driven jet stream in winter. There is support for this suggestion in several studies which identify four European-Atlantic regimes, of which three clearly represent shifts of the jet stream. However, we should note that the significance of the northern jet position is not as clear as the other two, both in the jet event analysis of Figure 2 and in the reproducibility test applied to the mixture model. If this regime is excluded the system collapses into the two-regime system proposed by Woollings et al. (2009), comprising a state with a separated subpolar jet and a Greenland blocking regime.

A system with just two preferred positions of the North Atlantic eddy-driven jet would be more in line with the behaviour in the South Pacific in the vicinity of the split jet stream (Figure 16f), and also with model results which suggest two distinct states depending on whether or not the subtropical and eddy-driven jets are separated (Akahori and Yoden 1997; Lee and Kim 2003; Chan and Plumb 2009). However, it is quite conceivable that the behaviour in the North Atlantic could differ from this. The strong northern hemisphere stationary wave pattern means that the North Atlantic eddy-driven jet and storm track tilt meridionally to an extent not seen elsewhere. Variability in 
this region is particularly large, in part because the subtropical jet is relatively weak and so does not overly constrain variability in the eddy-driven jet.

A key question is what mechanisms could be responsible for the existence of preferred jet stream locations? Transient eddy forcing (Figure 6) acts to reinforce the jet stream at its current location, but does so at all latitudes, not just the three preferred latitudes. Woollings et al. $(2008,2009)$ suggested the existence of a distinct regime in negative NAO space corresponding to the occurrence of blocking over Greenland. This regime is the same as the southern jet position identified here. The central jet position corresponds to days close to the peak of the 2D NAO/EA distribution, so a natural interpretation of this is an undisturbed state, which features separated subtropical and eddy-driven jets, as in the South Pacific (see the Appendix). One possible explanation for the existence of the third, northernmost jet location is that it reflects the occurrence of blocking over Southwest Europe which diverts the jet stream to the north. Persistent blocking events in this region are associated with anticyclonic Rossby wave-breaking (Tyrlis and Hoskins 2008). This may partly resolve the difference between the two-state system suggested by Woollings et al. $(2008,2009)$ and the three-state system of Benedict et al. (2004) and others, in which anticyclonic wave-breaking on the equatorward side of the jet acts to displace the jet to the north. Here, however, the northern preferred jet position is associated with a shift to more negative values of the EA, rather than more positive values of the NAO. Interestingly, blocking further north and east within Europe is remarkably decoupled from the latitude of the eddy-driven jet stream, consistent with the emergence of European blocking as a fourth distinct regime in several studies.

Finally, it is apparent in several of the results presented here that, over the North Atlantic in winter, the mean state of the system is significantly different from the most frequented state. The most frequented state corresponds to the central preferred jet position, and the system exhibits weaker tendencies when it is close to this state. The central jet position could be simply interpreted as an essentially unperturbed state, and so this may represent a better candidate for the basic state of the system than the mean state. Compared to the central jet position, the mean state exhibits a jet with weaker wind speeds (see Figure 11) which will also be broader due to the effect of time averaging (Swanson 2001; Fyfe and Lorenz 2005). Similar arguments apply elsewhere, such as in the vicinity of the split jet stream in the South Pacific, where the mean location of the jet represents a mixture of states with co-located and separated subtropical and eddy-driven jet streams.

\section{Acknowledgements}

We are indebted to ECMWF for providing the ERA-40 reanalysis data, and to Mike Blackburn for helpful discussions. We would like to thank the anonymous reviewers for their constructive comments.

\section{A Appendix: Comparison with other seasons and regions}

This appendix summarises the results of the jet latitude analysis of section 2 applied to other seasons and geographical regions. The distribution of North Atlantic jet latitude anomalies for the other seasons is shown in Figure 16a-c. In none 
of these is such clear multimodality evident, although the structure does seem quite similar in spring, when the kurtosis of the distribution is notably low. Distributions for other regions are shown in Figure 16d-f. In the Central North Pacific (Figure 16e) the distribution is very narrow and unimodal with high kurtosis, reflecting the inhibition of eddydriven variability by the very strong subtropical jet in this region (Nakamura and Sampe 2002; Lee and Kim 2003; Eichelberger and Hartmann 2007). The distribution is highly skewed, with large poleward shifts occurring much more often than large equatorward shifts. This seems to be in agreement with the asymmetry of the Pacific-North America pattern (Palmer 1988) which has a strong influence in this area. As shown by Barton and Ellis (2009), the jet is more variable further downstream in the Pacific. The distribution of jet latitude in the eastern North Pacific (Figure 16d) exhibits weak bimodality, and the distribution is wider than that upstream. Overall, the structure of the North Atlantic distribution is very different to that in the Pacific, but this is not too surprising. As described by Brayshaw et al. (2009) and Gerber and Vallis (2009), the Atlantic and Pacific jets are shaped differently by the stationary wave patterns arising from orography and sea surface temperature forcing. Over the Atlantic the storm track and eddy-driven jet have a pronounced southwest-northeast tilt, and the subtropical jet is relatively weak. This means that the eddy-driven jet is more easily separated from the subtropical jet (Lee and Kim 2003), for example during the positive phase of the NAO (Ambaum et al. 2001; Gerber and Vallis 2009).

Another interesting region is the South Pacific, in the vicinity of New Zealand and downstream, where the subtropical and eddy-driven jets appear separated even in the winter-mean wind field (e.g. Hoskins and Hodges 2005). The distribution of jet latitude for this area is shown in Figure 16f. The distribution is particularly broad, indicating large variability, with strong skewness suggesting that here also there are just two preferred positions of the jet. The mode of the distribution is at $-5^{\circ}$, but there is a sizeable set of days when the jet is located around 25 degrees further north than this. Composites of the wind field for these days (not shown) suggest that at these times the eddy-driven jet has merged with the subtropical jet. This suggests a possible physical interpretation for the shape of the distribution. There are just two preferred states of the eddy-driven jet: either it is co-located with the subtropical jet or it is in its usual position some thirty degrees to the south. Nakamura and Sampe (2002) suggest that in the North Pacific in midwinter, eddies become trapped in the strong subtropical jet. This means that meridional wave propagation and the associated eddy momentum fluxes are reduced (Eichelberger and Hartmann 2007). It seems possible that a similar mechanism operates here, so that if the eddy-driven jet is not sufficiently separated from the subtropical jet, the eddies become trapped within the subtropical jet and the two jets coalesce.

We have tested the significance of the apparent multimodality in all PDFs using the bootstrap test suggested by Silverman (1981). The null hypothesis $H_{0}^{k}$ is that the PDF has at most $k$ modes, and the alternative hypothesis, $H_{1}^{k}$ is that the PDF has more than $k$ modes. First the critical bandwidth $h_{c}$ is determined as the smallest window width that is consistent with $H_{0}^{k}$. One thousand bootstrap series are then sampled from the kernel density estimate using $h_{c}$ (the critical density). The p-value is then obtained by computing the probability that the estimated PDF has more than $k$ modes. Large values of these probabilities are in favour of rejecting the null hypothesis; Izenman and Sommer (1990) recommend a nominal value of 0.4 . For the smoothed bootstrap sampling we used randomly selected 30-day blocks of 
the original time series in order to retain the observed serial correlation.

Table I shows the probabilities obtained $(p)$, along with the critical window widths $\left(h_{c r i t}\right)$. For the North Atlantic in winter there is clear support for three modes, since $p$ is larger than 0.4 for the null hypotheses that there are at most one or two modes. For the remaining seasons the test suggests two modes in summer and one mode in spring. However, for the summer case the second mode is found in the extreme right-hand tail of the distribution, which is poorly populated and likely affected by topography, suggesting that this is an artefact and there is in fact only one mode. Of course, this does not preclude the existence of different regimes in the summer season. A closer examination of the PDF suggests that the skewness of the distribution can be modelled as a mixture of Gaussian components as in Hannachi (2007), but this is not pursued further here. No significant multimodality is found in spring, even though the estimated PDF with the optimal window width suggests three modes. It must be noted that the $p$ value in this case is very close to the nominal value of 0.4. In autumn the test supports the existence of four distinct modes, but it is clear from Figure 16 that these are not well separated.

For the East Pacific, three modes are supported by the test but again the third mode is located in the extreme right-hand tail of the distribution. Neglecting this leaves two modes as suggested by Figure 16. In the central Pacific the probabilities are all larger than the nominal value, suggesting there is just one mode. Finally, for the South Pacific the test is consistent with the existence of two modes.

\section{References}

Akahori, K. and Yoden, S. (1997). Zonal Flow Vacillation and Bimodality of Baroclinic Eddy Life Cycles in a Simple Global Circulation Model. Journal of Atmospheric Sciences, 54, 2349-2361.

Ambaum, M. H., Hoskins, B. J., and Stephenson, D. B. (2001). Arctic Oscillation or North Atlantic Oscillation? J. Climate, 14, 3945-3507.

Athanasiadis, P. J., Wallace, J. M., and Wettstein, J. J. (2009). Patterns of jet stream wintertime variability and their relationsip to the storm tracks. J. Atmos. Sci. Submitted.

Barnes, E. A. and Hartmann, D. L. (2009). Dynamical feedbacks and the persistence of the NAO. J. Atmos. Sci. In press.

Barton, N. P. and Ellis, A. W. (2009). Variability in wintertime position and strength of the North Pacific jet stream as represented by re-analysis data. International Journal of Climatology, 29, 851-862.

Benedict, J. J., Lee, S., and Feldstein, S. B. (2004). Synoptic view of the North Atlantic Oscillation. J. Atmos. Sci., 61(2), 121-144.

Blackmon, M. L. (1976). A Climatological Spectral Study of the $500 \mathrm{mb}$ Geopotential Height of the Northern Hemisphere. Journal of Atmospheric Sciences, 33, 1607-1623. 
Bordi, I., Fraedrich, K., Lunkeit, F., and Sutera, A. (2007). Tropospheric double jets, meridional cells and eddies: A case study and idealised simulations. Mon. Weather Rev., 135, 3118-3133.

Brayshaw, D. J., Hoskins, B., and Blackburn, M. (2009). The basic ingredients of the North Atlantic storm track. Part I: land-sea contrast and orography. J. Atmos. Sci., 66, 2429-2558.

Cassou, C. (2008). Intraseasonal interaction between the Madden-Julian Oscillation and the North Atlantic Oscillation. Nature, 455, 523-527.

Cassou, C., Terray, L., Hurrell, J. W., and Deser, C. (2004). North Atlantic Winter Climate Regimes: Spatial Asymmetry, Stationarity with Time, and Oceanic Forcing. Journal of Climate, 17, 1055-1068.

Chan, C. J. and Plumb, R. A. (2009). The Response to Stratospheric Forcing and its Dependence on the State of the Troposphere. J. Atmos. Sci., 66, 2107-2115.

Christiansen, B. (2007). Atmospheric Circulation Regimes: Can Cluster Analysis Provide the Number? Journal of Climate, 20, 2229-2250.

Corti, S., Molteni, F., and Palmer, T. N. (1999). Signature of recent climate change in frequencies of natural atmospheric circulation regimes. Nature, 398, 799-802.

Duchon, C. E. (1979). Lanczos Filtering in One and Two Dimensions. Journal of Applied Meteorology, 18, $1016-1022$.

Eichelberger, S. J. and Hartmann, D. L. (2007). Zonal jet structure and the leading mode of variability. J. Climate, 20, 5149-5163.

Franzke, C. and Feldstein, S. B. (2005). The Continuum and Dynamics of Northern Hemisphere Teleconnection Patterns. J. Atmos. Sci., 62, 3250-3267.

Franzke, C., Lee, S., and Feldstein, S. B. (2004). Is the North Atlantic Oscillation a breaking wave? J. Atmos. Sci., 61(2), 145-160.

Fyfe, J. C. and Lorenz, D. J. (2005). Characterizing Midlatitude Jet Variability: Lessons from a Simple GCM. Journal of Climate, 18, 3400-3404.

Gerber, E. P. and Vallis, G. K. (2009). On the Zonal Structure of the North Atlantic Oscillation and Annular Modes. J. Atmos. Sci., 66, 332-352.

Hannachi, A. (2007). Tropospheric Planetary Wave Dynamics and Mixture Modeling: Two Preferred Regimes and a Regime Shift. Journal of Atmospheric Sciences, 64, 3521-3541.

Hannachi, A. (2009). On the origin of planetary scale extratropical circulation regimes. J. Atmos. Sci. Accepted.

Hoskins, B. J. and Hodges, K. I. (2005). A New Perspective on Southern Hemisphere Storm Tracks. Journal of Climate, 18, 4108-4129. 
Hoskins, B. J., James, I. N., and White, G. H. (1983). The Shape, Propagation and Mean-Flow Interaction of LargeScale Weather Systems. J. Atmos. Sci., 40, 1595-1612.

Hsu, C. J. and Zwiers, F. (2001). Climate change in recurrent regimes and modes of Northern Hemisphere atmospheric variability. J. Geophys. Res., 106, 20145-20160.

Izenman, I. J. and Sommer, C. J. (1990). Philatelic mixtures and multimodal densities. J. Amer. Statist. Assoc., 83, 941-953.

Keeley, S. P. E., Sutton, R., and Shaffrey, L. (2009). Does the North Atlantic Oscillation show unusual persistence on intraseasonal timescales? Geophys. Res. Lett., 36, L22706.

Koch, P., Wernli, H., and Davies, H. C. (2006). An event-based jet-stream climatology and typology. International Journal of Climatology, 26, 283-301.

Kravtsov, S., Robertson, A. W., and Ghil, M. (2006). Multiple Regimes and Low-Frequency Oscillations in the Northern Hemisphere's Zonal-Mean Flow. Journal of Atmospheric Sciences, 63, 840-860.

Kunz, T., Fraedrich, K., and Lunkeit, F. (2009). Synoptic scale wave breaking and its potential to drive NAO-like circulation dipoles: A simplified GCM approach. Q. J. R. Meteorol. Soc., 135, 1-19.

Lau, N.-C. (1988). Variability of the observed midlatitude storm tracks in relation to low-frequency changes in the circulation pattern. J. Atmos. Sci., 45(19), 2718-2743.

Lee, S. and Kim, H.-K. (2003). The Dynamical Relationship between Subtropical and Eddy-Driven Jets. J. Atmos. Sci., 60, 1490-1503.

Lorenz, D. J. and Hartmann, D. L. (2003). Eddy-Zonal Flow Feedback in the Northern Hemisphere Winter. Journal of Climate, 16, 1212-1227.

Martius, O., Schwierz, C., and Davies, H. C. (2007). Breaking Waves at the Tropopause in the Wintertime Northern Hemisphere: Climatological Analyses of the Orientation and the Theoretical LC1/2 Classification. J. Atmos. Sci., 64, 2576-2592.

Masato, G., Hoskins, B. J., and Woollings, T. J. (2009). Can the Frequency of Blocking Be Described by a Red Noise Process? J. Atmos. Sci., 66, 2143-2149.

Michelangeli, P.-A., Vautard, R., and Legras, B. (1995). Weather Regimes: Recurrence and Quasi Stationarity. Journal of Atmospheric Sciences, 52, 1237-1256.

Monahan, A. H. and Fyfe, J. C. (2006). On the Nature of Zonal Jet EOFs. Journal of Climate, 19, 6409-6424.

Nakamura, H. and Sampe, T. (2002). Trapping of synoptic-scale disturbances into the North-Pacific subtropical jet core in midwinter. Geophys. Res. Lett., 29(16), 1761. 
Palmer, T. N. (1988). Medium and extended range predictability and stability of the Pacific/North American mode. Quarterly Journal of the Royal Meteorological Society, 114, 691-713.

Pelly, J. L. and Hoskins, B. J. (2003). A new perspective on blocking. J. Atmos. Sci., 60, 743-755.

Rivière, G. and Orlanski, I. (2007). Characteristics of the Atlantic Storm-Track Eddy Activity and Its Relation with the North Atlantic Oscillation. Journal of Atmospheric Sciences, 64, 241-266.

Silverman, B. W. (1981). Using Kernel Density Estimates to Investigate Multimodality. J. Roy. Stat. Soc., Ser. B., Volume 43, p. 97-99, 43, 97-99.

Sparrow, S. N., Blackburn, M., and Haigh, J. D. (2009). Annular variability and eddy zonal flow interactions in a simplified atmospheric GCM: Part 1 - Characterization of high and low frequency behaviour. J. Atmos. Sci. In press.

Strong, C. and Davis, R. E. (2008). Variability in the Position and Strength of Winter Jet Stream Cores Related to Northern Hemisphere Teleconnections. Journal of Climate, 21, 584-592.

Strong, C. and Magnusdottir, G. (2008). Tropospheric Rossby Wave Breaking and the NAO/NAM. Journal of Atmospheric Sciences, 65, 2861-2876.

Swanson, K. L. (2001). Upper-Tropospheric Potential Vorticity Fluctuations and the Dynamical Relevance of the Time Mean. Journal of Atmospheric Sciences, 58, 1815-1826.

Terrell, G. R. (1990). The maximal smoothing principle in density estimation. J. Amer. Statist. Assoc., 85, 470-477.

Thompson, D. W. J., Lee, S., and Baldwin, M. P. (2002). Atmospheric processes governing the Northern Hemisphere Annular Mode / North Atlantic Oscillation. In J. W. Hurrell, Y. Kushnir, G. Ottersen, and M. Visbeck, editors, The North Atlantic Oscillation: Climatic Significance and Environmental Impact, volume 134. AGU Geophysical Monograph Series.

Tyrlis, E. and Hoskins, B. J. (2008). The morphology of Northern Hemisphere blocking. J. Atmos. Sci., 65, 1653-1665.

Uppala, S. M. et al. (2005). The ERA-40 re-analysis. Q. J. R. Meteorol. Soc., 131(612), 2961-3012.

Vallis, G. K. and Gerber, E. (2008). Local and hemispheric dynamics of the North Atlantic Oscillation, annular patterns and the Zonal Index. Dynamics of Atmospheres and Oceans, 44, 184-212.

Vautard, R. (1990). Multiple weather regimes over the North Atlantic: Analysis of precursors and successors. Mon. Weather Rev., 118, 2056-2081.

Wittman, M. A. H., Charlton, A. J., and Polvani, L. M. (2005). On the Meridional Structure of Annular Modes. Journal of Climate, 18, 2119-2122.

Woollings, T., Hannachi, A., Hoskins, B., and Turner, A. (2009). A regime view of the North Atlantic Oscillation and its response to anthropogenic forcing. J. Climate. In press. 
Woollings, T. J., Hoskins, B. J., Blackburn, M., and Berrisford, P. (2008). A new Rossby wave-breaking interpretation of the North Atlantic Oscillation. J. Atmos. Sci., 65, 609-626. 


\begin{tabular}{lccccccccccccccc}
\hline & \multicolumn{2}{c}{ N ATL $(\mathrm{DJF})$} & \multicolumn{2}{c}{$(\mathrm{MAM})$} & \multicolumn{2}{c}{$(\mathrm{JJA})$} & \multicolumn{2}{c}{$(\mathrm{SON})$} & \multicolumn{2}{c}{ E PAC } & \multicolumn{3}{c}{ C PAC } & \multicolumn{2}{c}{ S PAC } \\
\hline Modes & $h_{\text {crit }}$ & $p$ & $h_{\text {crit }}$ & $p$ & $h_{\text {crit }}$ & $p$ & $h_{\text {crit }}$ & $p$ & $h_{\text {crit }}$ & $p$ & $h_{\text {crit }}$ & $p$ & $h_{\text {crit }}$ & $p$ \\
\hline 1 & 0.4 & 0.5 & 0.48 & 0.38 & 0.33 & 0.62 & 0.32 & 0.55 & 0.4 & 0.46 & 0.82 & 0.46 & 0.37 & 0.55 \\
2 & 0.31 & 0.61 & 0.29 & 0.4 & 0.2 & 0.3 & 0.26 & 0.62 & 0.3 & 0.47 & 0.2 & 0.45 & 0.2 & 0.02 \\
3 & 0.2 & 0.36 & 0.2 & 0.4 & 0.25 & 0.28 & 0.24 & 0.55 & 0.2 & 0.09 & 0.12 & 0.71 & - & - \\
\hline
\end{tabular}

Table I. Values of $h_{\text {crit }}$ and $p$ for the distributions shown in Figures 1 and 16 for various numbers of modes. See text for details.

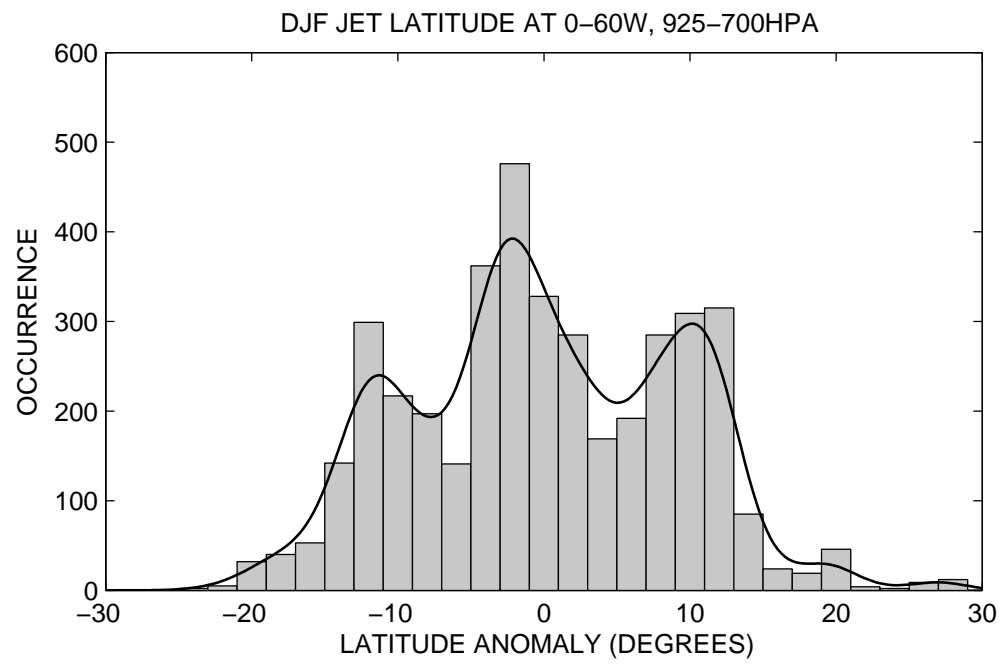

Figure 1. Distribution of the daily wintertime jet stream latitude anomalies in ERA-40, along with the kernel estimation of the PDF.

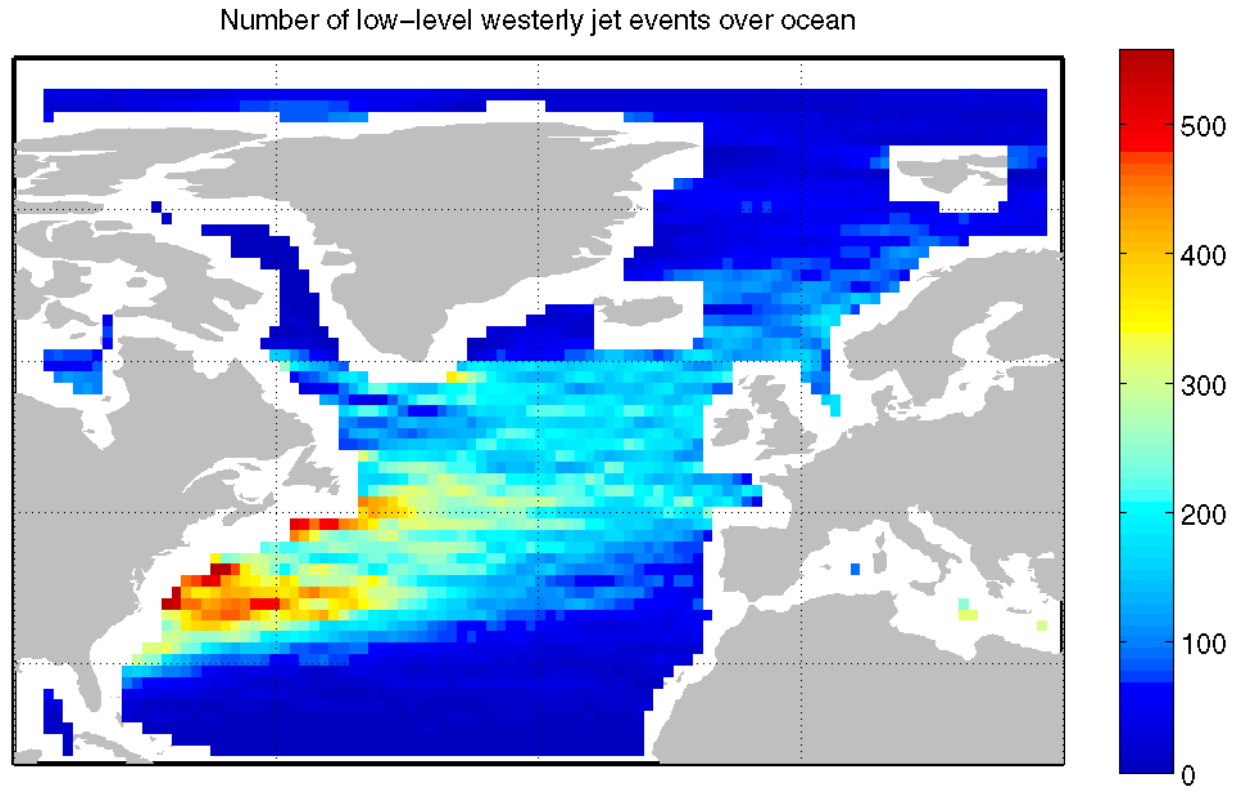

Figure 2. Occurrence of low-level westerly jet events over the North Atlantic in DJF. 
a) UNFILTERED ZONAL WIND (0-60W, 925-700HPA) FOR THE WINTER OF 2001/2002

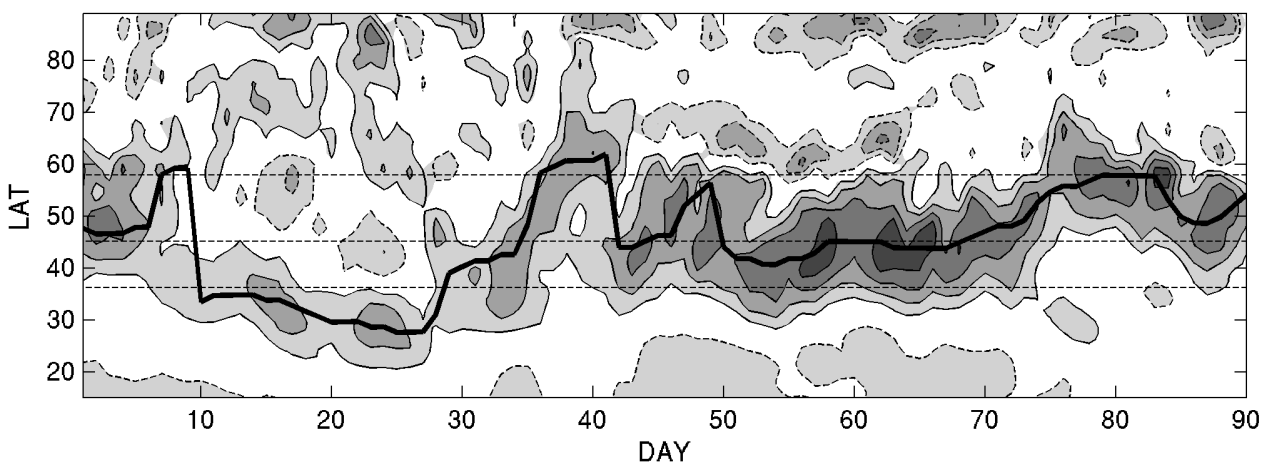

b) 10-DAY LOW-PASS ZONAL WIND (0-60W, 925-700HPA) FOR THE WINTER OF 2001/2002

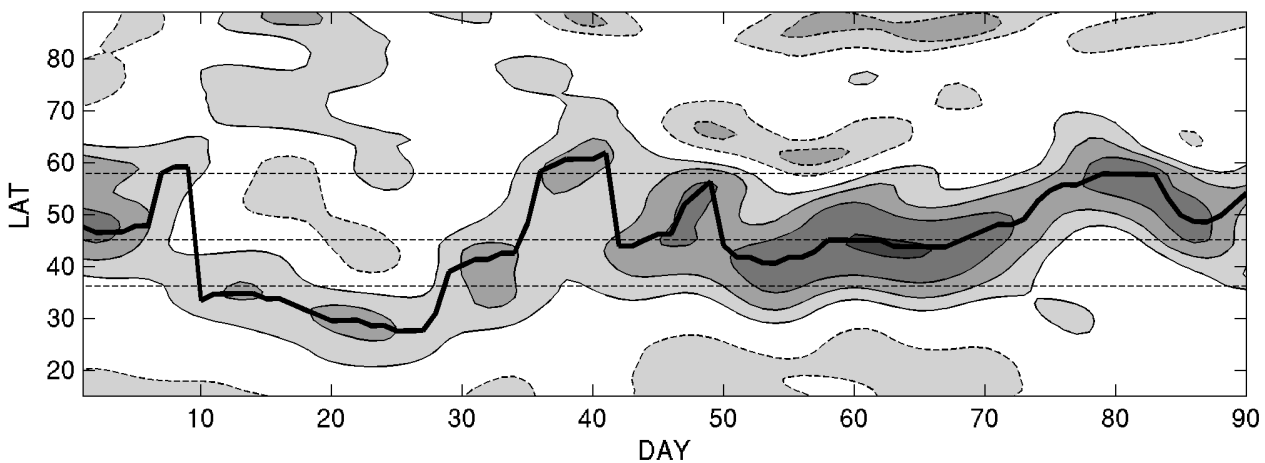

Figure 3. a) Hovmöller of the zonal wind averaged over $925-700 \mathrm{hPa}$ and $0-60^{\circ} \mathrm{W}$ for the winter of $2001 / 02$. The black line shows the latitude of the jet as identified by the method presented here. b) as a) but using the 10-day low-pass filtered winds. Contours are drawn every $5 \mathrm{~ms}^{-1}$ with negative contours dashed and the zero contour omitted. In both panels the average locations of the three preferred jet positions are shown by horizontal dashed lines.

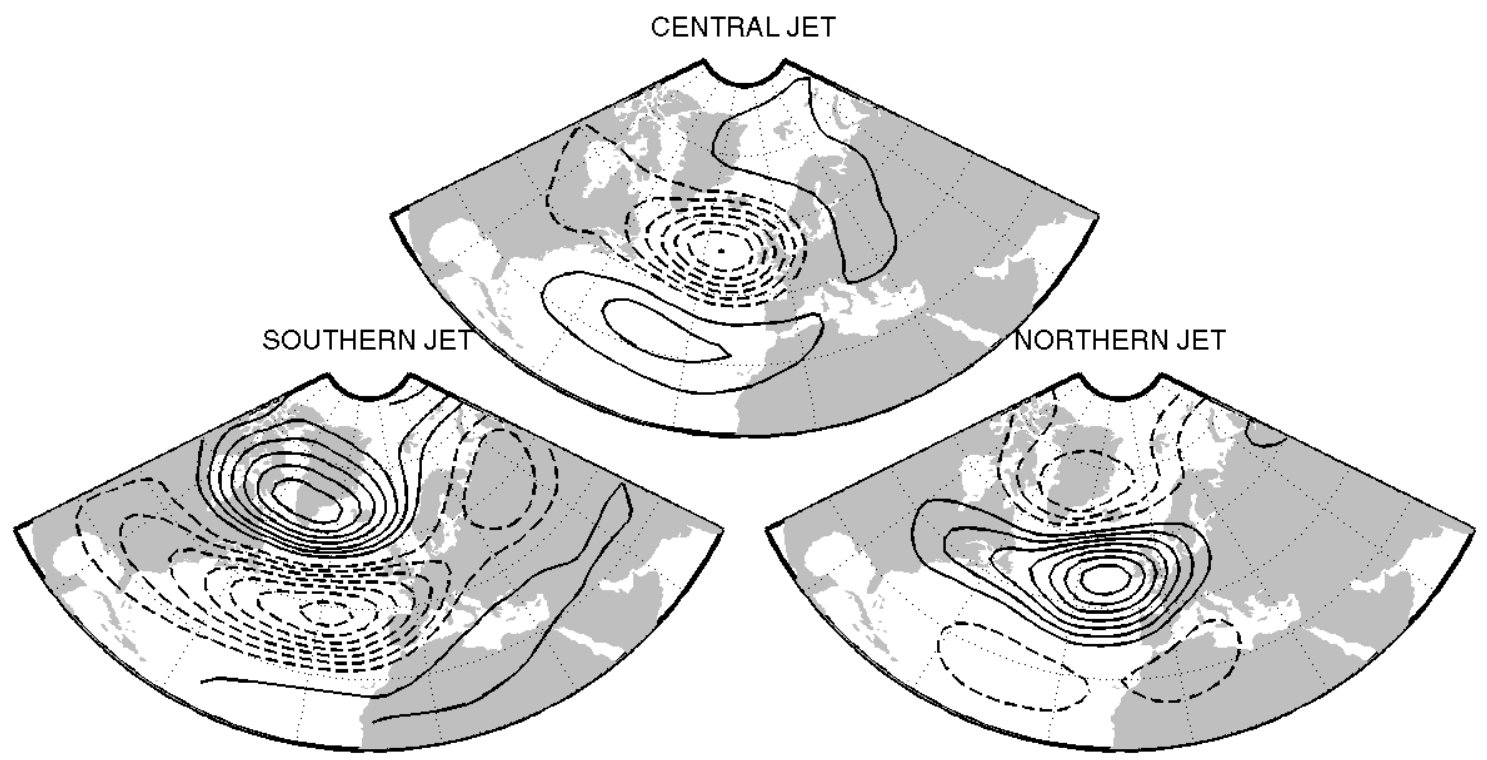

Figure 4. Z500 anomaly composites for the 300 days closest to each of the three maxima of the PDF in Figure 1, denoted the southern, central and northern jet locations from left to right in the PDF. Contours are drawn every $20 \mathrm{~m}$ with the zero contour omitted. 

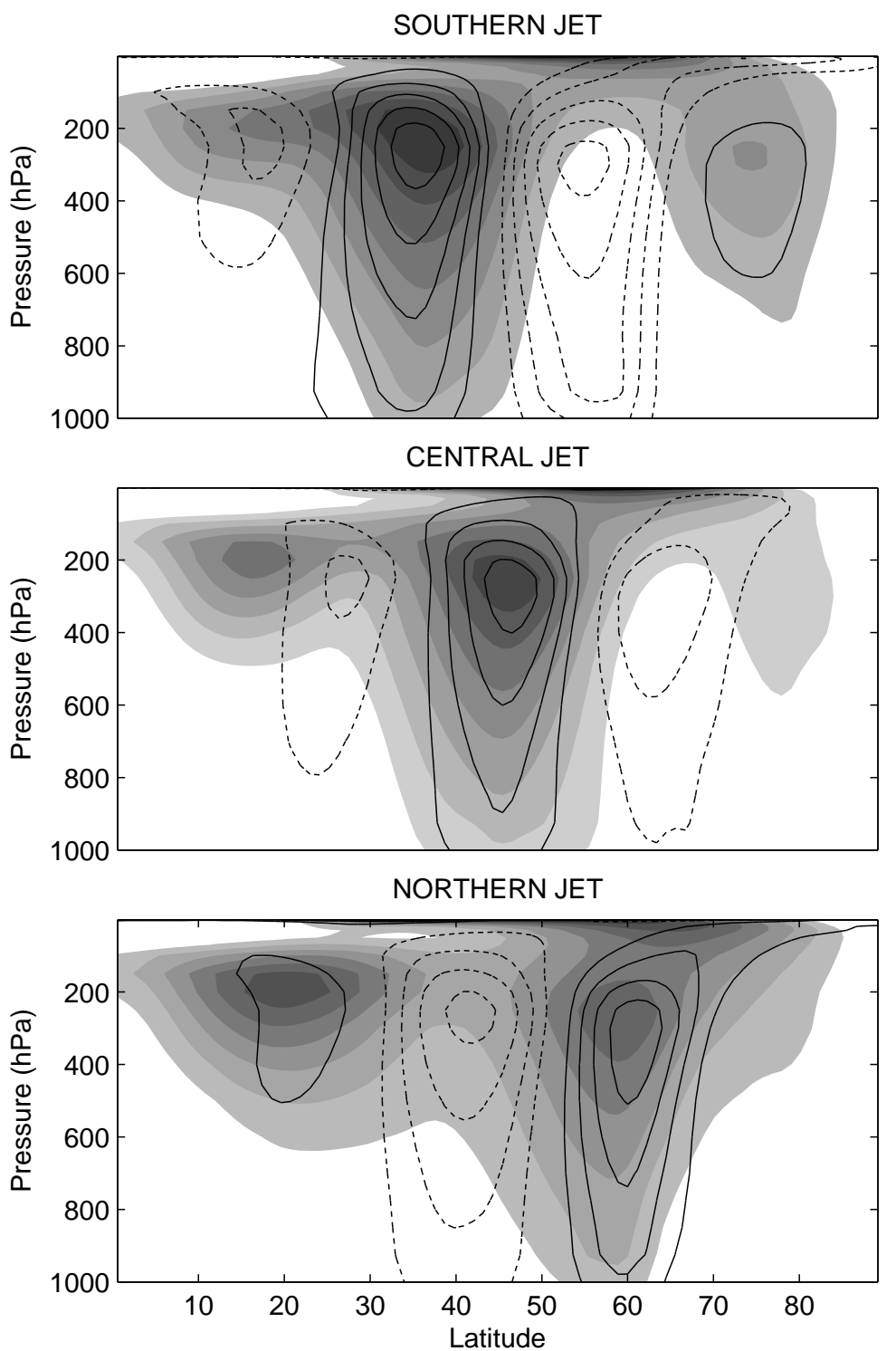

Figure 5. Composites of the zonal wind averaged over $0-60^{\circ} \mathrm{W}$ for the three jet stream locations. Shading shows the full field contoured every $5 \mathrm{~ms}^{-1}$, with the lowest contour drawn at $5 \mathrm{~ms}^{-1}$. Contour lines show anomalies from the DJF climatology at $3 \mathrm{~ms}^{-1}$ intervals, with negative contours dashed and the zero contour omitted. 


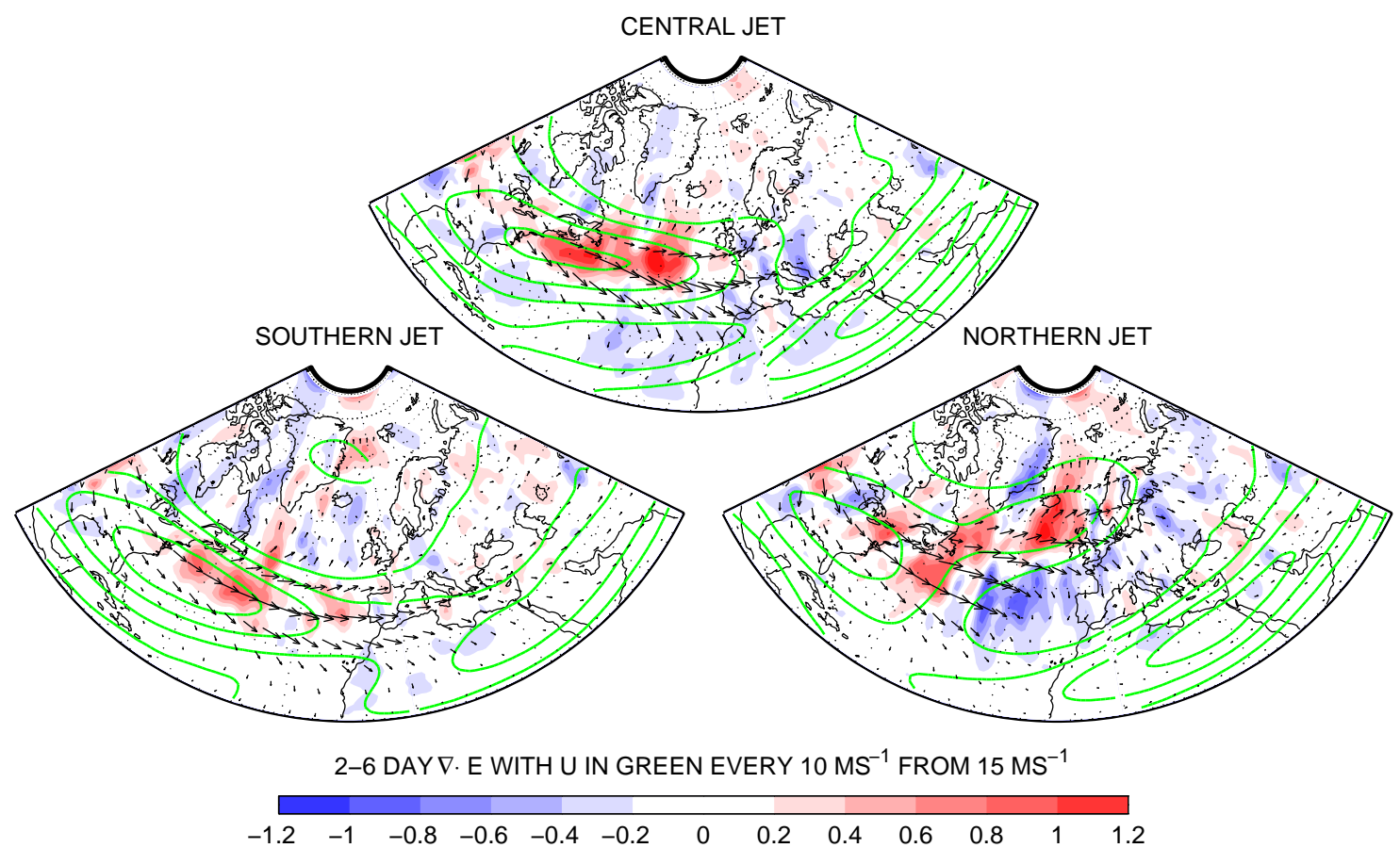

Figure 6. Composites of the zonal wind at $250 \mathrm{hPa}$ for the three jet stream locations, contoured in green at $15,25,35$ and $45 \mathrm{~ms}^{-1}$. Arrows indicate the composite $\mathbf{E}$-vectors of the 2-6 day bandpass filtered wind field, with $\nabla \cdot \mathbf{E}$ shaded (scaled by $10^{4}$ ).

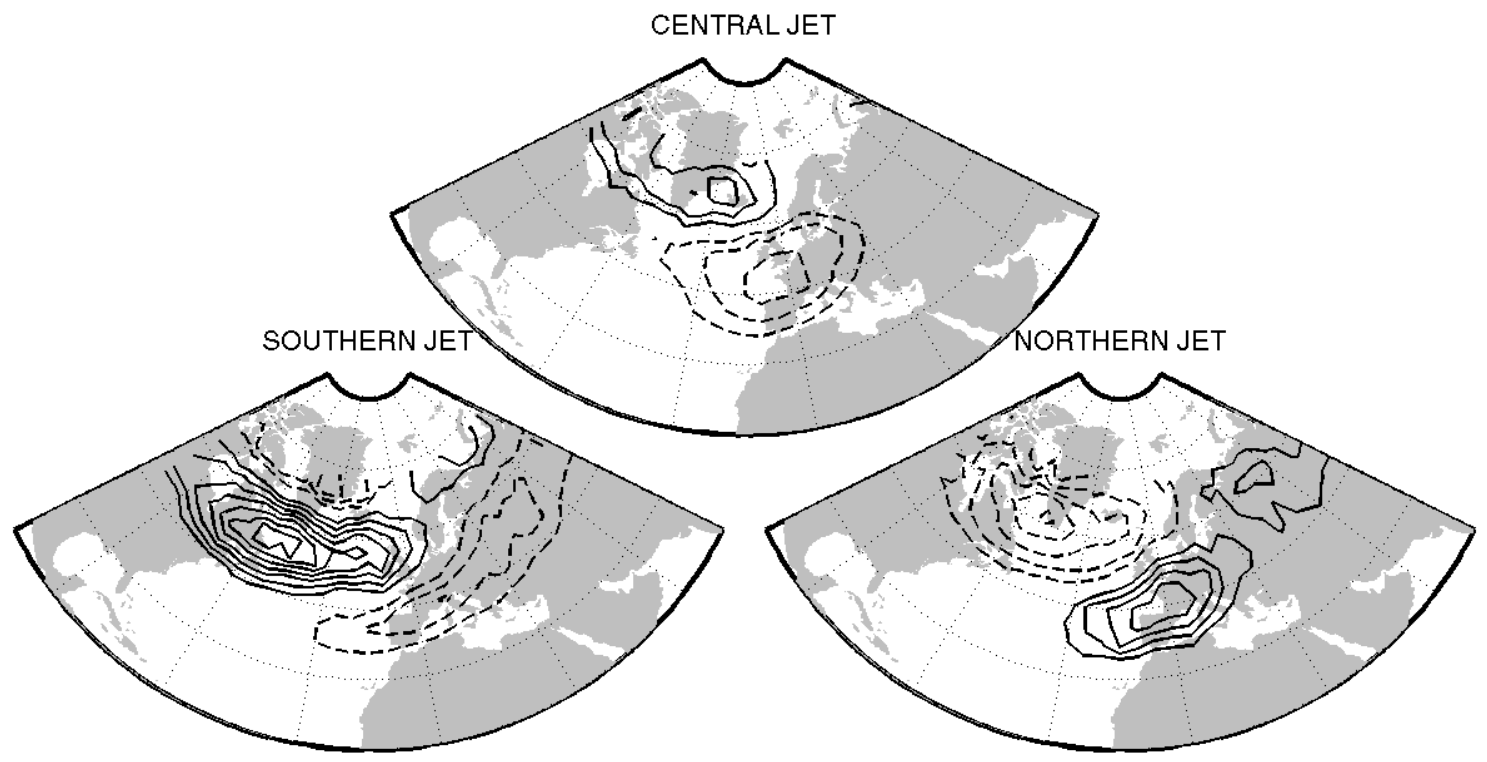

Figure 7. Composites of wave-breaking occurrence for the days corresponding to the three jet locations. These are shown as anomalies from the DJF climatological mean occurrence, contoured every 0.05 day ${ }^{-1}$. 


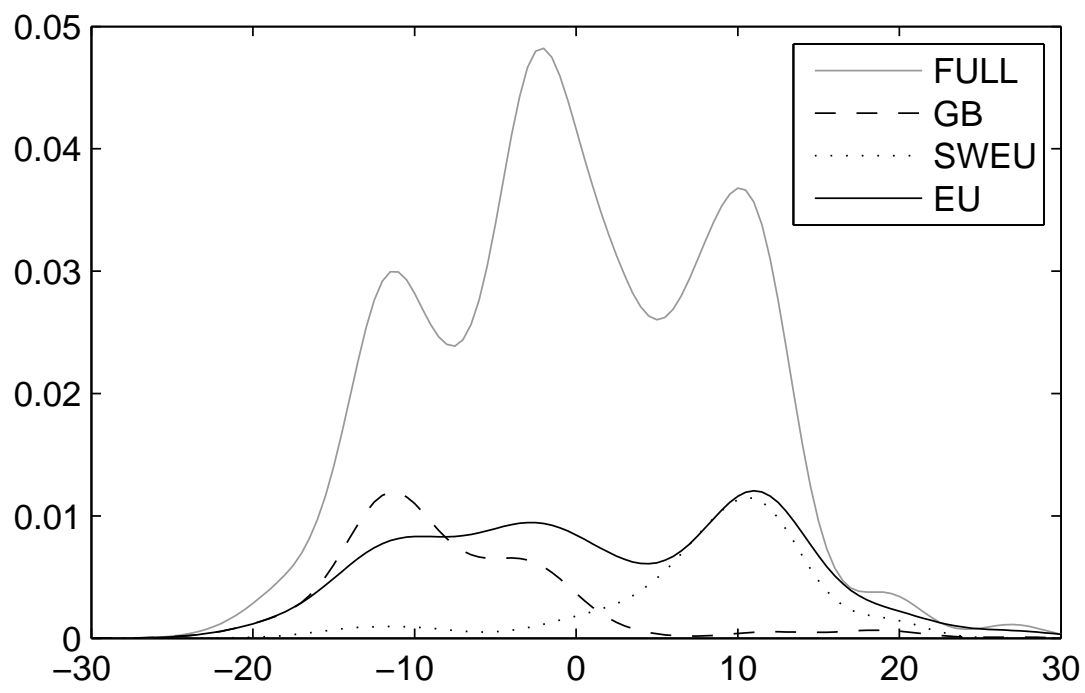

Figure 8. Kernel estimates of the PDF of jet latitude, as in Figure 1, but for days exhibiting blocking over different locations (GB: Greenland Blocking, $\left(53^{\circ} \mathrm{N}, 50^{\circ} \mathrm{W}\right)$; SWEU: South-west Europe, $\left(41^{\circ} \mathrm{N}, 15^{\circ} \mathrm{W}\right)$; EU: Europe, $\left.\left(53^{\circ} \mathrm{N}, 15^{\circ} \mathrm{E}\right)\right)$. The PDF of the full dataset is shown in grey and the other PDFs have been scaled by the number of days in each set.

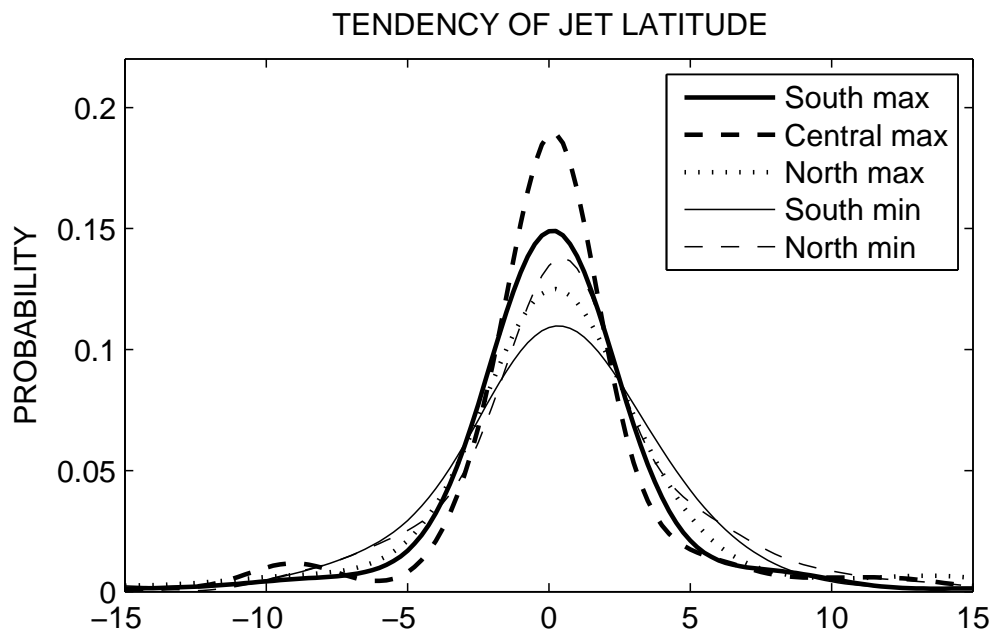

Figure 9. Kernel PDF estimates of the tendency in jet stream latitude for 300 days around each of the three maxima and the two minima of the jet stream latitude PDF in Figure 1. The tendency is the change in latitude over 48 hours. 

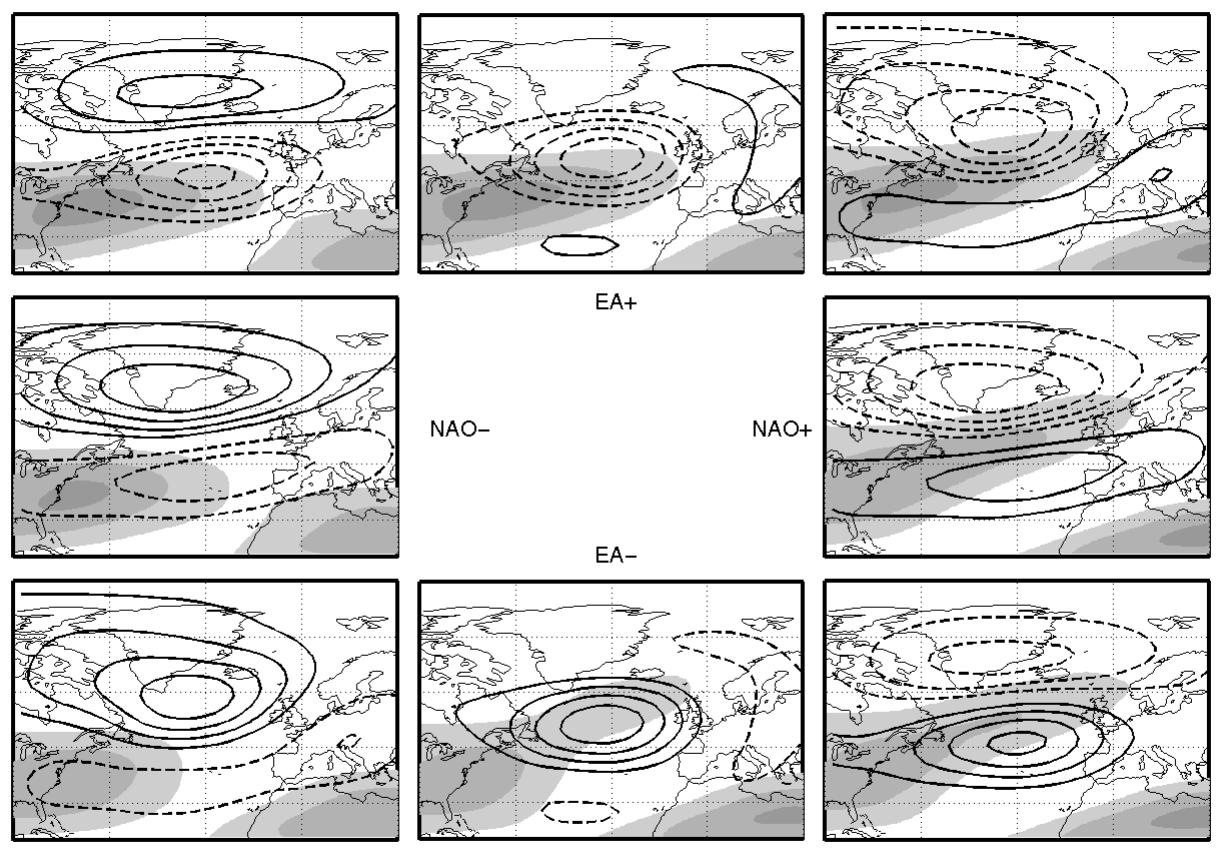

Figure 10. Summary of the circulation at different locations in NAO/EA space. The horizontal axis of the grid of plots is the NAO and the vertical axis is the EA. Z500 anomalies are contoured every $20 \mathrm{~m}$ per standard deviation of the principal component time series, and $300 \mathrm{hPa}$ zonal wind is shaded every $10 \mathrm{~ms}^{-1}$ starting at $20 \mathrm{~ms}^{-1}$. The corner plots are given by adding the respective NAO and EA maps and scaling by $1 / \sqrt{2}$.
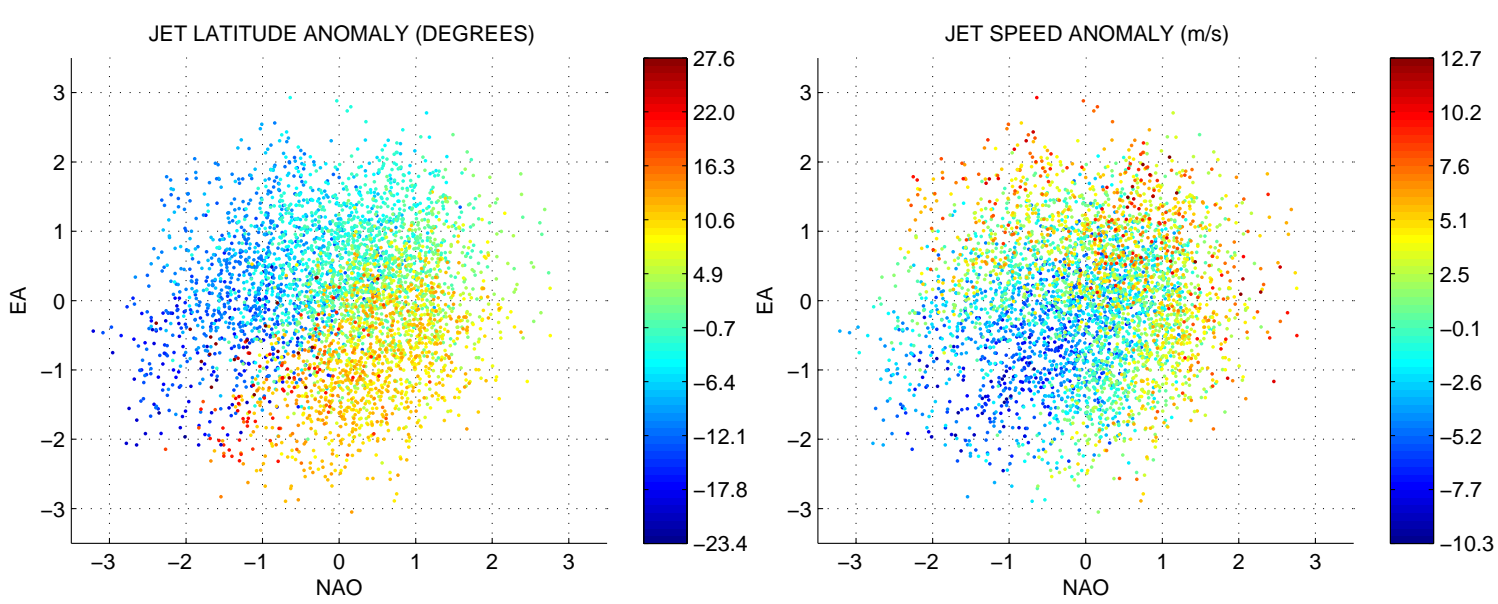

Figure 11. Scatterplot of normalised daily NAO and EA indices, with points coloured by the jet latitude (left) and jet speed (right). 


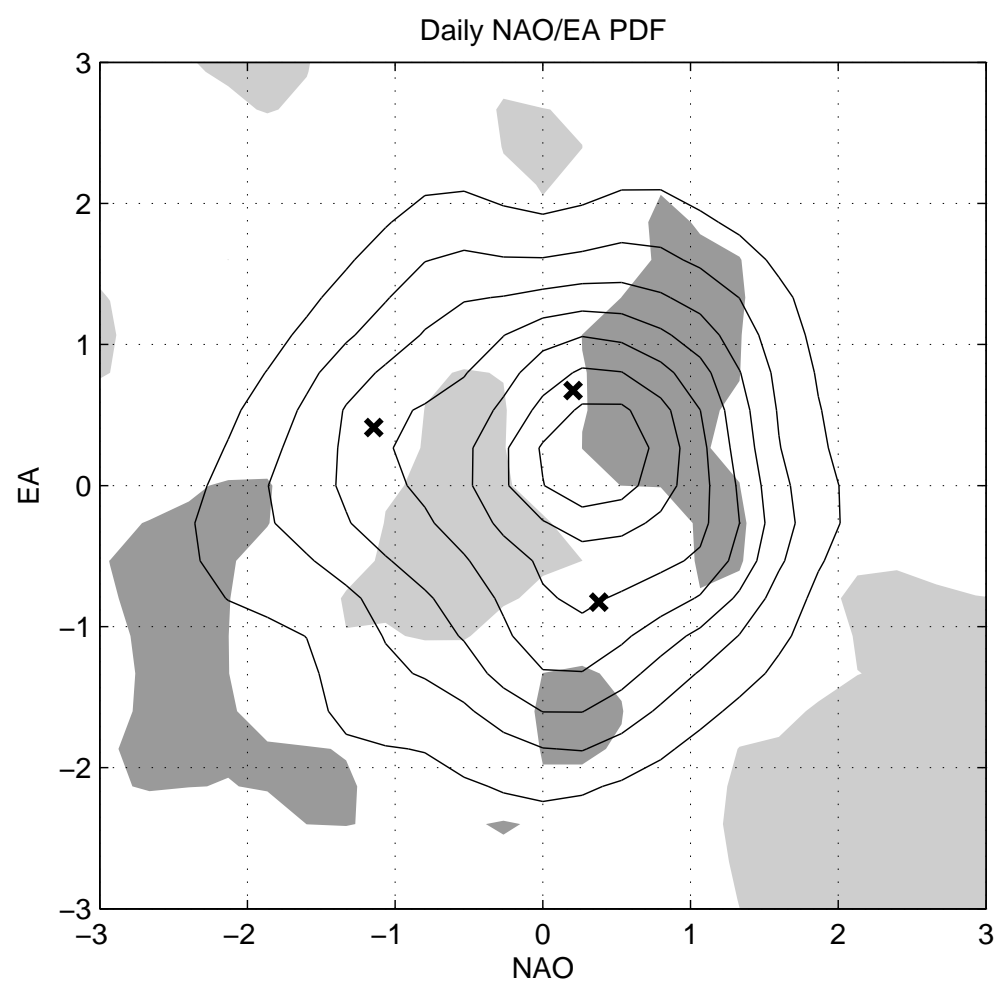

Figure 12. Kernel estimate of the 2D PDF of the daily NAO/EA distribution, with the probability contoured every 0.02 . Shading marks areas where the probability is outside the $95 \%$ range of 1000 AR1 simulations, with light shading for low probabilities and dark shading for high probabilities. The locations of the three composites of Figure 4 are marked with crosses.

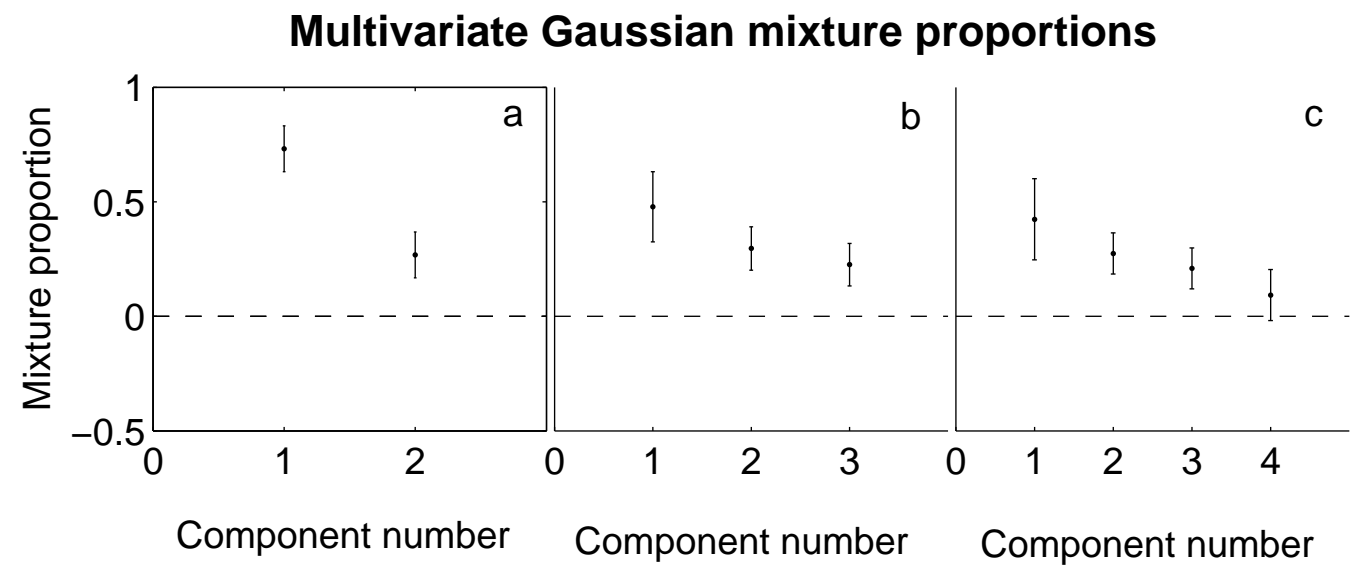

Figure 13. Mixing proportions for 2, 3 and 4 component mixture model estimations of the daily NAO/EA distribution, along with $95 \%$ confidence intervals. 

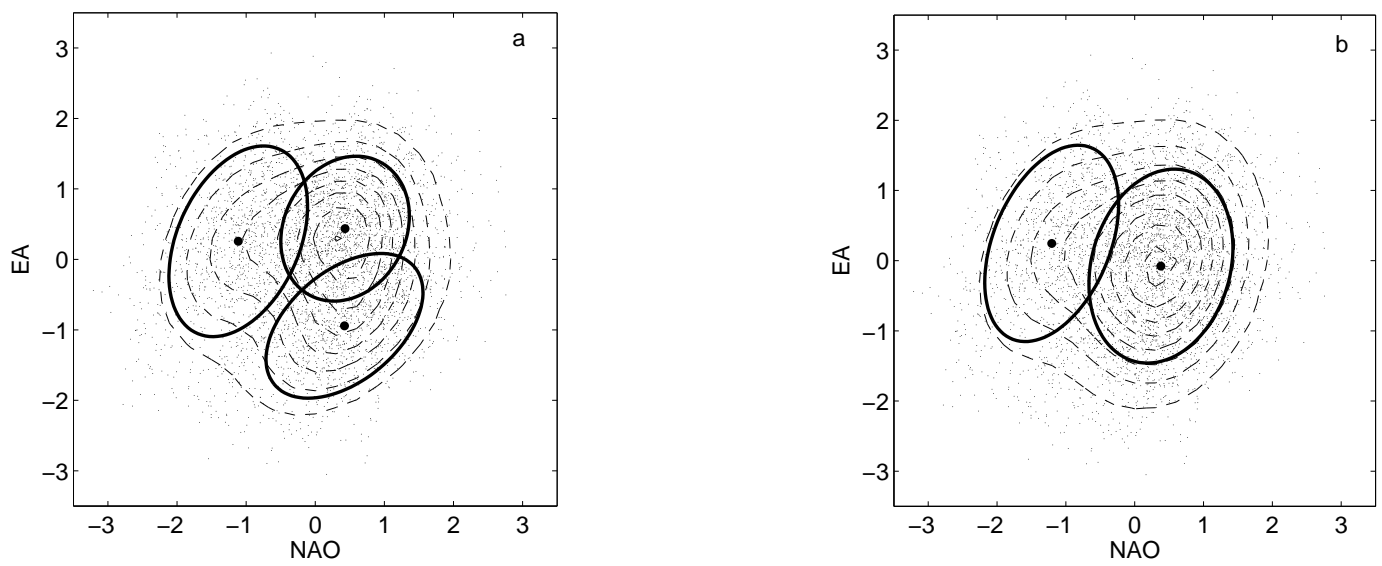

Figure 14. Mixture model estimates of the NAO/EA PDF using a) 3 and b) 2 Gaussian components. The solid contours indicate each of the Gaussian components, with $84 \%$ of the mass of the corresponding component contained within the contour.

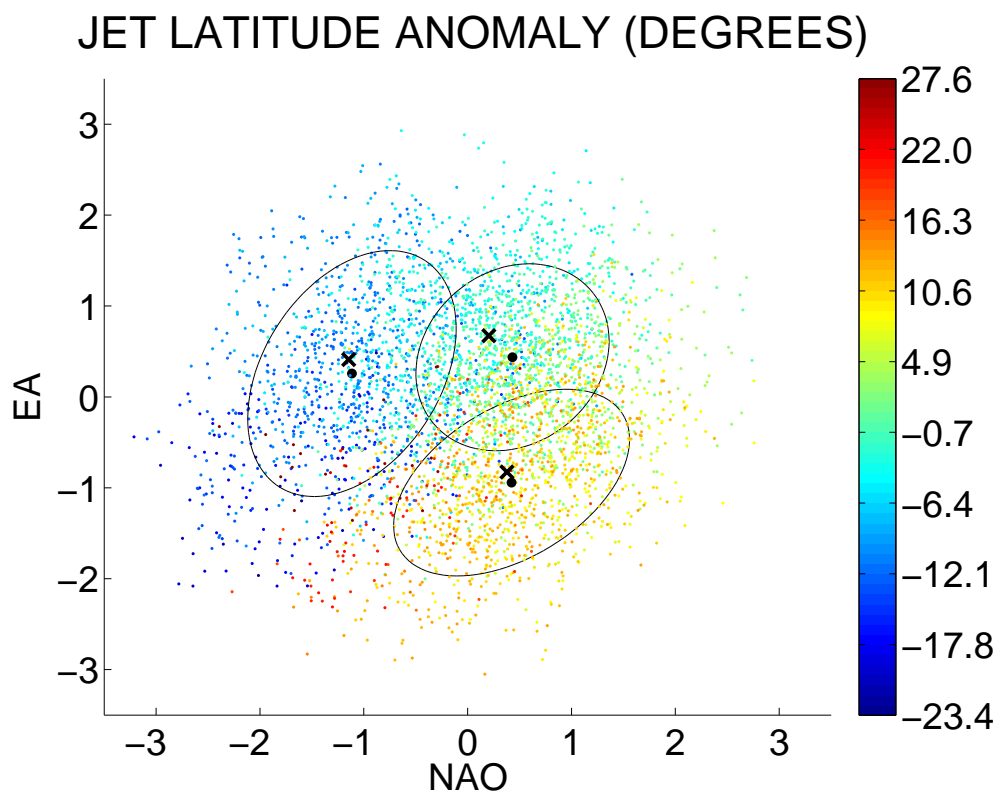

Figure 15. Three component mixture model estimate of the NAO/EA PDF. The three Gaussian components are shown in solid contours with their centres marked by dots. The crosses mark the locations of the preferred jet positions as in Figure 12, and the colouring is the jet latitude anomaly as in Figure 11. 
a) N ATL (0-60W) MAM

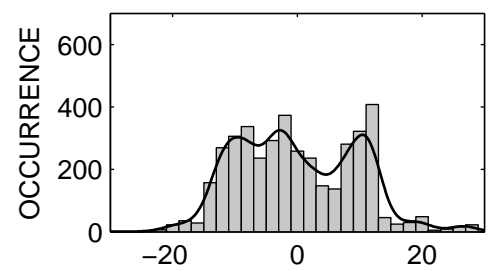

d) E PAC (200-240E) DJF

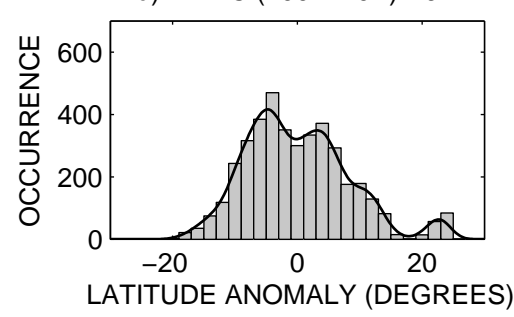

b) N ATL (0-60W) JJA

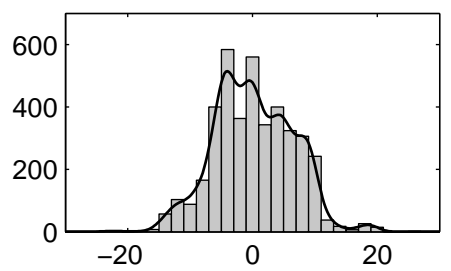

e) C PAC (150-210E) DJF

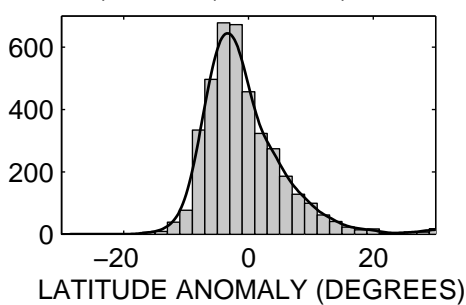

c) N ATL $(0-60 \mathrm{~W}) \mathrm{SON}$

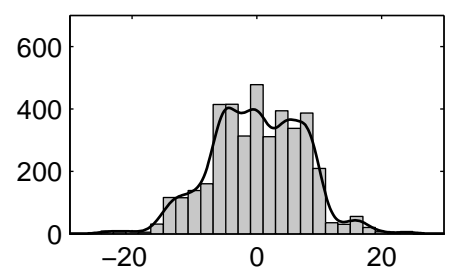

f) S PAC (180-240E) JJA

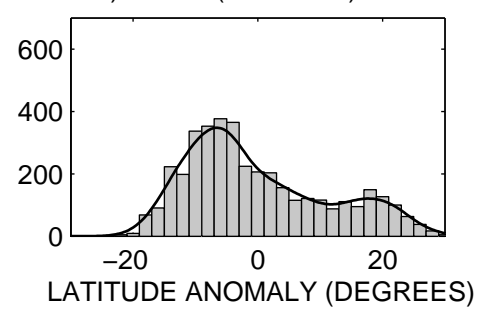

Figure 16. Distributions and PDFs of the jet stream latitude in the North Atlantic in other seasons (a-c) and in other regions in winter (d-f). 